\title{
CONTAGEM DE CÉLULAS SOMÁTICAS, CONTAGEM BACTERIANA TOTAL E ANÁLISES FÍSICO-QUÍMICAS DO LEITE PRODUZIDO NA REGIÃO SUL DO ESTADO DE GOIÁS
}

\author{
Nariane Coelho de Oliveira', Milena de Lima Vieira', Wallacy Barbacena Rosa dos Santos², Aline \\ Sousa Camargos², Jeferson Corrêa Ribeiro², Andréia Santos Cezário², Eliandra Maria Bianchini \\ Oliveira², Tiago Neves Pereira Valente ${ }^{3}$ \\ ${ }^{1}$ Instituto Federal de Educação, Ciência e Tecnologia Goiano - IFGOIANO, Curso de Zootecnia, Morrinhos, GO. \\ ${ }^{2}$ Instituto Federal de Educação, Ciência e Tecnologia Goiano - IFGOIANO, Dept. de Zootecnia, Morrinhos, GO. \\ ${ }^{3}$ Instituto Federal de Educação, Ciência e Tecnologia Goiano - IFGOIANO, Dept. de Zootecnia, Posse, GO. E-mail: \\ narianecoelho@gmail.com
}

\section{RESUMO}

Considerando que a produção de leite no Estado de Goiás vem passando por mudanças na cadeia produtiva que refletem diretamente no cenário nacional, estudos são necessários para obter informações sobre a qualidade do leite produzido nessa região. O presente trabalho foi realizado em parceria com a cooperativa receptora da produção de leite das propriedades rurais estudadas. Objetivou-se com o presente estudo avaliar a incidência da contagem de células somáticas (CCS), contagem bacteriana total (CBT) e a composição físico-química no leite, do rebanho leiteiro da região sul do estado de Goiás. Foram tabulados os dados da CCS, CBT e as análises físico-químicas, referentes ao período de agosto de 2015 a julho de 2016. As amostras foram coletadas mensalmente no tanque de resfriamento das propriedades e enviadas para um laboratório credenciado pela Rede Brasileira de Qualidade do Leite (RBQL). Constatou-se altos valores na CCS, porém, mantendo-se ainda dentro do permitido pela Instrução Normativa 62. Para a CBT houve resultados alarmantes, por estarem com índices além do permitido pela legislação em vigência. Em relação as variáveis de composição físico-químicas, nesse estudos foram utilizadas lactose, gordura e proteína total. Comparando os resultados obtidos durante o período experimental, com os da Instrução Normativa 62, observa-se que os teores de proteína total e gordura encontram-se dentro do padrão estabelecido.

Palavras-chave: composição; gado de leite; glândula mamária; qualidade do leite.

\section{SOMATIC CELL COUNT, TOTAL BACTERIAL COUNT AND PHYSICO-CHEMICAL ANALYSIS OF MILK PRODUCED IN THE SOUTH REGION OF THE STATE OF GOIÁS}

\begin{abstract}
Considering that the production of milk in the State of Goiás has undergone changes in the productive chain that reflect directly in the national scenario, studies are needed to obtain information on the quality of milk produced in this region. The present work was carried out in partnership with the cooperative receiving the milk production of the rural properties studied. The objective of this study was to evaluate the incidence of somatic cell count (CCS), total bacterial count (CBT) and the physicochemical composition of dairy herds in the southern region of the state of Goiás. The data of CCS, CBT and physicochemical analyzes were tabulated, from of period of August of 2015 to July of 2016. The samples were collected monthly in the cooling pond of the farms and sent to a laboratory accredited by the Brazilian Quality Milk Network (RBQL). High values were found in the CCS, however, remaining within the limits allowed by Normative Instruction 62. For CBT were found alarming results, as they were indexed beyond what is allowed by the regulation. Regarding the physical-chemical composition variables, this study were used
\end{abstract}


lactose, fat and total protein. Comparing the results obtained during the experimental period with those of Normative Instruction 62, were observed that the total protein and fat contents are within the established standard.

Keywords: composition; dairy cattle; mammary gland; quality of milk.

\section{INTRODUÇÃO}

O leite e seus derivados são considerados produtos importantes, principalmente pelo seu alto valor nutritivo e geração de renda, por meio da criação de empregos diretos e indiretos, contribuindo, dessa forma, para evitar o êxodo rural, pois, é importante para que futuramente possa suprir as demandas da população e indústria láctea, que tende a aumentar, e paralelamente havendo maior preocupação por parte da população a respeito da qualidade do leite.

Mesmo sendo destaque nacional na agropecuária, devido à sua elevada produção de leite, o estado de Goiás não possui dados satisfatórios relativos à qualidade do leite bovino. Mas, é possível observar crescente preocupação a respeito do tema, tanto por parte da indústria de laticínios quanto pelos órgãos de regulação e fiscalização.

Nesse sentido, o Ministério da Agricultura, Pecuária e Abastecimento (MAPA) publicou, em 29 de dezembro de 2011 a Instrução Normativa no 62 (IN 62), onde regulamenta a produção, identidade, qualidade, coleta e transporte do leite cru, do leite tipo $A$, refrigerado e leite pasteurizado. A IN 62, substitui a IN 51, alterando basicamente as regulamentações que regem os parâmetros de qualidade do leite.

A qualidade do leite que sai da propriedade, é determinante para a qualidade do leite processado, pois mesmo pasteurizando adequadamente o leite, ainda haverá degradação das proteínas, açucares e a gordura da matéria prima, por meio de enzimas dos microrganismos que ainda estarão presentes nos produtos lácteos. O leite de vaca é composto de cerca de $87,5 \%$ de água e a porção sólida sendo composta por 4,6 \% de lactose, 3,8\% de gordura, 3,3\% de proteína, e $0,8 \%$ de sais minerais e vitaminas (BLOWEY, 1992).

Para Santos (2016) a proteína, a gordura e a lactose são os principais constituintes, da porção sólida do leite. Porém, do ponto de vista nutricional, somente a proteína e a gordura são consideradas importantes. Leite com altos teores de sólidos indica que as vacas estão sendo bem alimentadas, o que aumenta a produção individual e total do rebanho.

Como uma medida padrão de qualidade do leite, tem-se utilizado bastante a contagem celular somática (CCS), pois essa medida possui extrema relação com a composição, rendimento industrial e segurança alimentar do leite. Segundo Santos (2001), a CCS possui alta relevância para os produtores rurais, porque indica o estado sanitário das glândulas mamárias das vacas.

Para Vargas et al., (2014) a determinação da contagem bacteriana total (CBT) do leite de tanques de expansão é muito importante para avaliação da higiene de ordenha e das condições de estocagem e transporte do leite cru, sendo uma ótima ferramenta no controle da qualidade da matéria prima, permitindo inferir sobre os prováveis efeitos indesejáveis acerca do rendimento industrial de produtos lácteos.

A melhoria da qualidade do leite e derivados produzidos no Brasil permitirá que o país não apenas importe, como também exporte os produtos lácteos com maior intensidade. Diante do exposto, objetivou-se com o presente estudo quantificar a CCS, CBT e a composição físico-química (gordura, proteína total e lactose) do leite produzido na região sul do estado de Goiás, e comparálas com os valores estabelecidos pela legislação vigente. 


\section{MATERIAL E MÉTODOS}

O presente estudo foi realizado na região sul do estado de Goiás, onde o clima da região recebe a classificação Aw (tropical estacional de savana) no sistema de Köppen, com inverno seco e verão quente. Essa região caracteriza-se por apresentar uma atividade leiteira desenvolvida por pequenos, médios e grandes proprietários rurais. Para o referente estudo foi criada uma amostra homogênea, de forma que as propriedades selecionadas caracterizassem com confiabilidade 0 perfil da produção leiteira da região.

Em parceria com a Cooperativa Mista dos Produtores de Leite de Morrinhos - Complem, foram obtidos dados das produções mensais de aproximadamente 800 propriedades leiteiras do sul do estado. Contendo propriedades com baixa (0 a 100L/leite/dia), média (100L a $300 \mathrm{~L} /$ leite/dia) e alta (>300L/leite/dia) produtividade. Os dados coletados são referentes ao período de agosto de 2015 a julho de 2016.

Os dados foram obtidos por meio de análises laboratoriais de amostras de leite retiradas dos tanques de expansão de cada propriedade, assim gerando dados mensais de composição. Os dados também foram comparados nas diferentes estações do ano, onde temos para o Hemisfério Sul a primavera que começa no dia 21 de setembro e vai até 20 de dezembro, verão de 21 de dezembro até 20 de março, outono de 21 de março até 20 de junho e inverno de 21 de junho até 20 de setembro.

Os resultados obtidos foram tabulados e submetidos à estatística descritiva e processados com o uso do programa Microsoft Office Excel 2013. Os valores foram analisados e comparados aos padrões estabelecidos pela instrução normativa 62 .

\section{RESULTADOS E DISCUSSÃO}

Foram feitas as médias dos resultados obtidos dos componentes do leite, produzido em alguns municípios da região sul do estado de Goiás, que é captado pela Cooperativa Mista dos Produtores de Leite de Morrinhos - Complem. As médias são mensais, e equivalem ao período de agosto de 2015 a julho de 2016 (Tabela 1). Os valores de CCS encontraram-se levemente elevados, porém, mantendo-se ainda dentro do permitido pela legislação. A CBT apresentou valores muito acima do estabelecido para referida Normativa. Valores elevados da CBT, demonstram a necessidade de uma investigação das possíveis fontes de contaminação do leite na região.

Os resultados obtidos das análises laboratoriais a respeito da contagem bacteriana total e contagem celular somática, durante o período de cada estação do ano, estão contidos nas figuras 1 e 2, respectivamente. Os valores de CCS encontraram - se levemente elevados, porém, sem sofrer extremas oscilações, independentemente da estação do ano, mantendo-se ainda dentro do permitido pela legislação. Entretanto, valores da CBT acima do permitido pela legislação são alarmantes para a região sul do estado de Goiás, uma vez que, em nenhuma das estações do ano houve redução expressiva do valor da CBT no leite.

A indústria láctea tem por obrigação enviar, ao menos uma vez por mês, amostras do leite de cada produtor para análise em laboratório credenciado na Rede Brasileira de Laboratórios de Controle de Qualidade do Leite (RBQL). Com isso, o MAPA terá viabilidade de acompanhar a qualidade do leite em cada propriedade rural, tendo base para traçar estratégias de melhorias da qualidade do produto. 
Tabela 1. Médias mensais dos resultados dos componentes do leite: contagem celular somática $(\mathrm{mL})$ e bacteriana total ( $\mathrm{ufc} / \mathrm{mL}$ ).

\begin{tabular}{lcc}
\hline Mês & CCS & CBT \\
\hline Agosto/2015 & 302.295 & 133.485 \\
Setembro/2015 & 318.391 & 123.553 \\
Outubro/2015 & 347.734 & 163.306 \\
Novembro/2015 & 361.080 & 215.434 \\
Dezembro/2015 & 375.256 & 179.294 \\
Janeiro/2016 & 383.597 & 214.511 \\
Fevereiro/2016 & 367.324 & 247.517 \\
Março/2016 & 364.909 & 285.115 \\
Abril/2016 & 352.915 & 249.147 \\
Maio/2016 & 355.602 & 268.003 \\
Junho/2016 & 343.723 & 206.704 \\
Julho/2016 & 351.655 & 230.194 \\
\hline
\end{tabular}

CCS - Contagem de células somáticas.

CBT - Contagem bacteriana total.

A Instrução Normativa 62 (IN 62), que substitui a Instrução Normativa 51 (IN 51), desde 29 de dezembro de 2011, classifica os tratamentos utilizados no leite em três categorias: Leite do tipo A, que é encaminhado diretamente da ordenha para o resfriador sem que haja contato com o meio externo e contendo no mínimo $2,9 \%$ de proteína e $3 \%$ de gordura. Leite do tipo B, é o leite que tem contato com o meio externo por ser oriundo de ordenha manual, armazenado em resfriador que fica na fazenda até 48 horas, mas que encontre no mínimo de 2,9\% de proteína e $3 \%$ de gordura. Leite do tipo $C$, também oriundo de ordenha manual, porém, que não passa por qualquer tratamento dentro da fazenda, sendo entregue no laticínio após no máximo duas horas da ordenha, e o limite mínimo para a proteína é $2,9 \%$ e de gordura 3\%. A IN 62 estabelece que o leite deve ser analisado em laboratórios credenciados para que haja o monitoramento de sua qualidade (BRASIL, 2011).

Conforme a IN 62, as porcentagens mínimas para gordura e proteína total do leite refrigerado são 3,0 e 2,9\% respectivamente. Havendo as médias dos resultados obtidos durante o período experimental (Tabela 2), e comparando-os com os valores mínimos estipulados pela Instrução Normativa 62, observa-se que os teores de gordura e proteína total, encontram-se dentro do padrão estabelecido. Não há valores mínimos exigidos para a lactose, pois, do ponto de vista nutricional, somente a proteína e a gordura são consideradas importantes.

Em estudos conduzidos por Nakamura et al. (2012), após correlacionarem às variáveis climáticas (temperatura máxima e mínima, precipitação pluviométrica e a umidade relativa) e a qualidade do leite (CBT, CCS, sólidos totais, gordura, proteína e lactose), observaram que as variáveis climáticas que afetam a qualidade do leite são as temperaturas máximas e mínima, sendo inversamente proporcional, ao teor de gordura, proteína e sólidos totais, e diretamente proporcional para a lactose, entretanto, a CCS e CBT foram influenciadas de forma positiva pela precipitação e umidade relativa, e concluíram que a partir dos resultados da pesquisa, é possível afirmar que os fatores climáticos interferem diretamente na qualidade do leite. 
Figura 1. Médias estacionais dos resultados laboratoriais da contagem bacteriana total (ufc/mL).
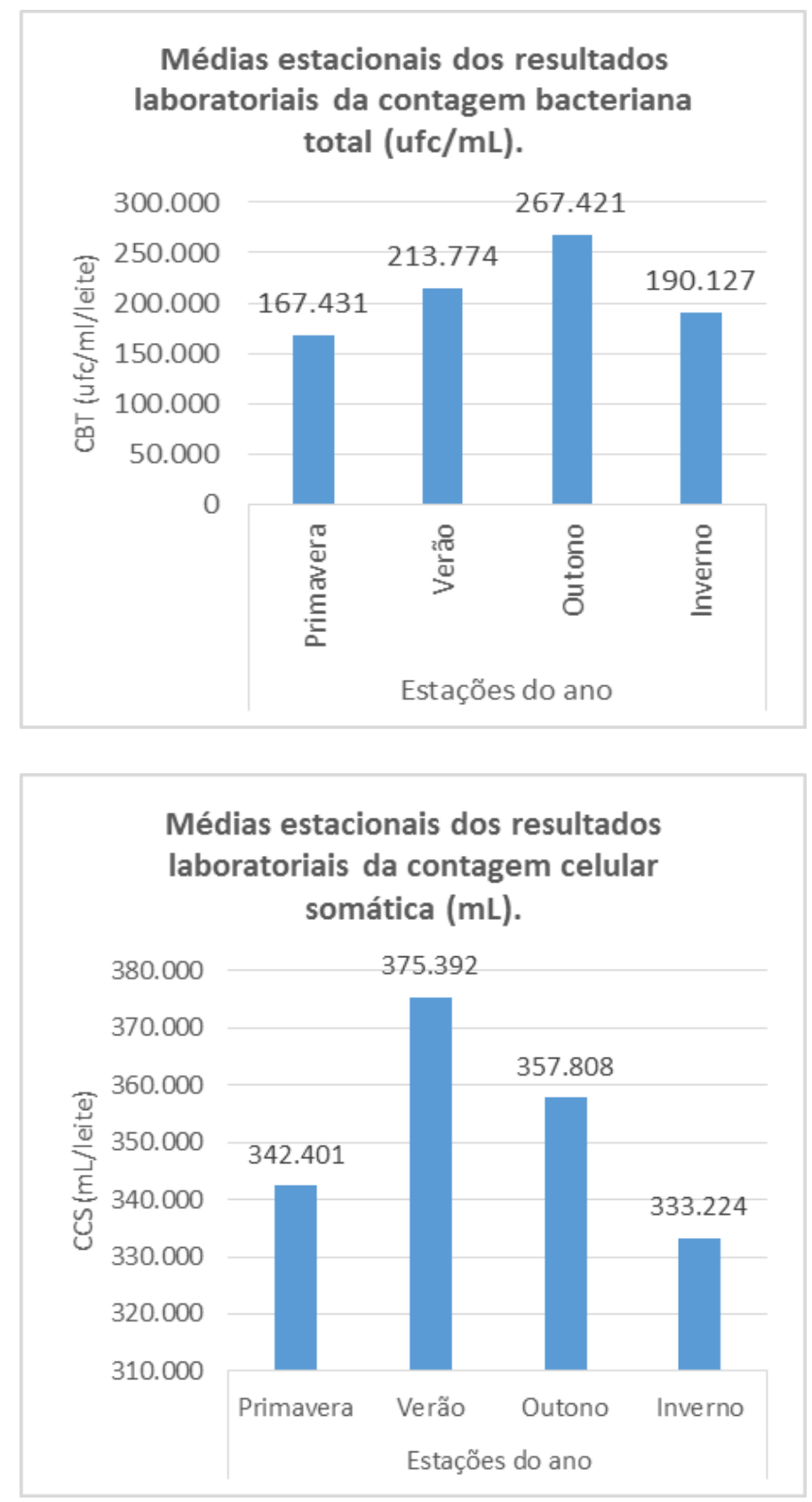

Estudos conduzidos por Silva et al. (2010) mostraram que ao avaliarem a qualidade do leite cru refrigerado estocado em propriedades rurais, nos períodos seco e chuvoso, os resultados médios da CCS foram mais elevados no período seco $4,9 \times 105$ $\mathrm{CS} / \mathrm{mL}$, sendo que no período chuvoso a CCS foi de $2,9 \times 105 \mathrm{CS} / \mathrm{mL}$. 
Tabela 2. Médias das variáveis estudadas: lactose, gordura e proteína total, em (\%).

\begin{tabular}{llcl}
\hline \multicolumn{1}{c}{ Meses } & Lactose & Gordura & Proteína Total \\
\hline Agosto/2015 & 4,611 & 3,502 & 3,237 \\
Setembro/2015 & 4,602 & 3,337 & 3,132 \\
Outubro/2015 & 4,626 & 3,259 & 3,111 \\
Novembro/2015 & 4,591 & 3,269 & 3,228 \\
Dezembro/2015 & 4,593 & 3,389 & 3,290 \\
Janeiro/2016 & 4,605 & 3,518 & 3,318 \\
Fevereiro/2016 & 4,617 & 3,629 & 3,351 \\
Março/2016 & 4,663 & 3,695 & 3,424 \\
Abril/2016 & 4,514 & 3,707 & 3,378 \\
Maio/2016 & 4,474 & 3,813 & 3,380 \\
Junho/2016 & 4,507 & 3,712 & 3,325 \\
Julho/2016 & 4,526 & 3,589 & 3,276 \\
\hline
\end{tabular}

A contagem de células somáticas do leite sofre variação por meio de diversos fatores, como a idade do animal, estresse, época do ano e alimentação, porém, a mastite é considerada o fator mais preocupante. Pelo fato da mastite ser uma reação inflamatória da glândula mamária, que tem por objetivo combater as ações negativas bacterianas, químicas, térmicas ou mecânicas e caracterizando-se por alterações físico-químicas, celulares e bacteriológicas do leite, além de modificações patológicas do tecido glandular (NASCIF JR., 2001).

Vargas et al. (2014) ao avaliarem o efeito da contagem bacteriana total (CBT) sobre os constituintes do leite, verificando a influência que as variáveis climáticas exercem sobre a CBT, concluíram que a elevação da CBT está diretamente correlacionada com o aumento dos teores de gordura, proteína, minerais e sólidos totais, o que não deve ser considerado favorável à qualidade do leite, pois, o incremento dos valores de CBT é influenciado por todos os utensílios que entram em contato com o leite, pele de tetos e úbere, bem como glândula mamária infectada, principalmente por estreptococos causadores de mastite subclínica, e em relação as variáveis climáticas, não houve relação significativa entre o logaritmo natural da CBT normal e as variáveis climáticas (temperatura ambiente, umidade relativa do ar e precipitação pluviométrica).

Entretanto, Andrade et al. (2009) observaram uma baixa na concentração de gordura em decorrência da elevação da CBT, o que poderia estar relacionado com a ação de fosfolipases de origem bacteriana, principalmente a fosfolipase $\mathrm{C}$ e a lecitinase, das bactérias psicotróficas, que são microrganismos capazes de se desenvolver em temperaturas abaixo de 7 으, sendo os principais agentes de deterioração do leite cru refrigerado.

\section{CONCLUSÃO}

Houve altos valores na CCS, porém, mantendo-se ainda dentro do permitido pela legislação. Para a CBT houve resultados alarmantes, por estarem com índices além do permitido pela legislação, tendo as estações verão e outono com as maiores taxas, o que serve de alerta aos produtores e indústrias na obtenção e processamento de leite com qualidade higiênico-sanitária adequada. Para os teores de proteína total e gordura foram encontrados resultados dentro dos padrões estabelecido pela Instrução Normativa 62.

\section{REFERÊNCIAS}

ANDRADE, U.V.C.; HARTMAN, W.; MASSON, M.L. Isolamento microbiológico, contagem de células somáticas e contagem bacteriana total em amostras de leite. Ars Veterinaria, v. 25, n. 3, p. 129135, 2009. 
BLOWEY, R.W. Factors affecting milk quality. In: Andrews, A. H. et al. Ed. Bovine Medicine. Diseases and husbandry of cattle. Blackwell, Oxford. 1992. p. 329-334.

BRASIL. Instrução Normativa n. 62 de 29 de dezembro de 2011. Dispões sobre regulamentos técnicos aplicados ao leite cru refrigerado e pasteurizado. Diário Oficial da República Federativa do Brasil, Brasília, 31 dez. de 2011. Seção 1, p. 6. 2011.

NAKAMURA, A.Y. et al. Correlação entre as variáveis climáticas e a qualidade do leite de amostras obtidas em três regiões do estado do Paraná. Arq. Ciênc. Vet. Zool. UNIPAR, Umuarama, v. 15, n. 2, p. 103108, jul./dez. 2012.

NASCIF JR., I.A. Diagnóstico da mastite subclínica bovina pela condutividade elétrica do leite, cmt e contagem de células somáticas: influência das estações do ano, fases da lactação e ordenhas da manhã e da tarde. Jaboticabal: Universidade Estadual Paulista, 2001. 47p. Dissertação (Mestrado em Zootecnia) - Universidade Estadual Paulista, 2001.

SANTOS, M.V. Contagem de células somáticas e qualidade do leite e derivados. In: SIMPÓSIO INTERNACIONAL SOBRE PRODUÇÃO INTENSIVA DE LEITE, 5., 2001, Belo Horizonte. Anais... São Paulo: Instituto Fernando Costa, 2001. p.115-127.

SANTOS, M.V. Qualidade do Leite ao redor do mundo. Disponível em: http://www.milkpoint.com.br/mn/radarestecnicos/artigo.asp?area=16\&area_desc=Qualidade+do +leite\&id_artigo=87. Acesso em: 28 janeiro. 2017.

SILVA, M.A.P. et al. Variação da qualidade do leite cru refrigerado em função do período do ano e do tipo de ordenha. Revista do Instituto Adolfo Lutz, v. 69, n. 1, p. 112-118, 2010.

VARGAS, D.P. et al. Correlações entre contagem bacteriana total e parâmetros de qualidade do leite. Revista Brasileira de Ciência Veterinária, v. 20, n. 4, 2014. 